\title{
Prevalence of Helicobacter pylori Infection in Samples of Gastric Biopsies
}

\author{
Leda Maria Delmondes Freitas Trindade ${ }^{\mathrm{a}, \mathrm{d}}$, Lania Barreto de Oliveira Menezes ${ }^{\mathrm{a}}$, \\ Adozina Marques de Souza Neta ${ }^{a}$, Paulo Candido Leite Rolemberg ${ }^{a}$, Lais Dantas Souza ${ }^{a}$, \\ Ikaro Daniel de Carvalho Barreto ${ }^{\mathrm{b}}$, Luise Meurer ${ }^{\mathrm{c}}$
}

\begin{abstract}
Background: Helicobacter pylori (H. pylori) infection affects about $50 \%$ of the world population and its association with environmental factors and host properties is involved in gastric carcinogenesis. The study aimed to estimate the prevalence of $H$. pylori in samples of gastric mucosa biopsies, correlate the presence of the bacteria in the sample with the variables age, sex and origin, to identify the types of lesions found in patients with H. pylori, and to evaluate the association of the lesions with the region of the gastric mucosa.
\end{abstract}

Methods: A cross-sectional, retrospective study was carried out in Aracaju, Sergipe, Brazil, from January 2013 to December 2015. A total of 45,206 gastric mucosal biopsies were obtained from patients submitted to upper gastrointestinal endoscopy. Of the reports evaluated, 12,909 met the inclusion criteria since they presented the patient's demographic data as well as the histopathological characteristics of gastric mucosal regions and positivity for $H$. pylori. Data were analyzed by IBM SPSS Statistic 20 and subjected to descriptive analyses (categorical variables) and inferential (Pearson's Qui-square and linear association tests) and multiple correspondence analyses. Significance level adopted 5\%.

Results: Of the total of $12,909(28.6 \%)$ reports evaluated, $67 \%$ $(8,647)$ came from urban areas and $64.5 \%(8,320)$ were female. The mean age (standard deviation (SD)) was 43 years, ranging from 8 to 100 years, prevailing between 21 and 60 years. Among the types of gastric mucosa analyzed, $95.5 \%(12,322)$ were of the antral mucosa. The absence of glandular atrophy, the mild infection intensity for $H$. pylori, the absence of metaplasia, the presence of foveolar hyperplasia and lymphoid follicles were statistically significant $(\mathrm{P}<0.001)$ in this region. In the fundic region, the evidence of fibrinoleucocytic

Manuscript accepted for publication February 06, 2017

aDepartment of Medicine, Tiradentes University, Aracaju 49032-490, Brazil bBiometrics and Applied Statistics - PPGBEA - UFRPE, Aracaju 49160-000, Brazil

'Department of Gastroenterology and Hepatology, Laboratory of Pathological Anatomy Dra. Monica Araujo (LAPMA), Aracaju 49015-230, Brazil

${ }^{\mathrm{d} C}$ Corresponding Author: Leda Maria Delmondes Freitas Trindade, Department of Medicine, Tiradentes University, 300 Murilo Dantas Ave., Aracaju 49032490, Brazil. Email: ledeltrin@gmail.com

doi: https://doi.org/10.14740/gr785w crust and lymphoid follicles was significant $(\mathrm{P}<0.001)$. There was no evidence of associated ulcerated lesions or significant relationship with intestinal metaplasia in the antral mucosa, whereas the fundic mucosa had a strong association with lymphoid follicles. The prevalence of active $H$. pylori infection in this study was $30.93 \%$.

Conclusion: Detection rate of $H$. pylori and its association with acute and chronic inflammation should be taken into account. The antral region has shown higher incidence and the presence of $H$. pylori was strongly associated with foveolar hyperplasia and lymphoid follicles.

Keywords: Helicobacter pylori; Gastric mucosa; Prevalence of Helicobacter pylori; Atrophy; Intestinal metaplasia

\section{Introduction}

For over 100 years, micro-organisms have been observed in the gastric tissue, and its association with gastritis has been known since the 1970s. In 1982, Marshall and Warren identified and cultivated Campylobacter pyloridis, later called Helicobacter pylori (H. pylori) [1].

$H$. pylori is a spiral-shaped gram-negative and microaerophilic [2]. Its ability to proliferate and survive in the gastric environment is due to factors such as the production of urease by the microorganism, its motility and ability to adhere to the gastric epithelium. The way through which the infection occurs remains unknown. However, person to person transmission appears to be the most likely one, either through fecal-oral or oral-oral exposure [3].

Conservative approaches to this issue suggest that $50 \%$ of the population is affected by $H$. pylori and it is considered the commonest bacterial infection in humans [4]. Genetic sequencing analysis suggests that humans have been infected with $H$. pylori since their first migration from Africa some 58,000 years ago [5]. Once acquired, the infection persists and may or may not produce gastroduodenal disease [3]. The prevalence of the infection varies according to age, socioeconomic status and ethnicity. Socioeconomic status is also an important determinant and inversely correlated to $H$. pylori infection [6]. Furthermore, within any age range, the infection appears to be more common amongst blacks and Hispanics compared to whites [7].

In developing countries, where most children are infected 
before the age of 10 , the prevalence in adults reaches more than $80 \%$ before aged 50 . In developed countries, like the United States, the evidence of the infection among children is very unlikely to happen, but it becomes more common during adulthood [7]. The increase in the prevalence of infection with age was initially thought to represent a continuous rate of acquisition of the bacterium throughout the life. However, new epidemiological evidence indicates that most infections are acquired during childhood, even in developed countries [7].

Recent studies [6] suggest that, in developing countries, such as Iran, hygiene practices in childhood and family education determine the prevalence of the infection. In Japan, from 1950 on, there was a rapid decline of the infection rate attributed to the economic progress of the post-war period and improved sanitation [8]. The quality of life and socioeconomic conditions should be considered risk factors to acquire $H$. $p y$ lori infection [9].

The chronic inflammation induced by $H$. pylori interferes with the normal physiology of the gastric acid secretion in different degrees, thus leading to chronic gastritis, which, in most individuals, remains asymptomatic and does not progress. However, in some cases, altered gastric secretion, associated with tissue injury, induces the development of peptic ulcer, whereas in other cases, gastritis progresses to atrophy, intestinal metaplasia, and eventually to gastric carcinoma or rarely to gastric lymphoma, due to the persistent immune stimulation of the lymphoid tissue [10].

The gastritis can be classified based on the severity of the mucosal lesion as erosive or non-erosive, according to the site of gastric involvement (cardia, body and antrum) and histologically, as acute or chronic based on the type of inflammatory cell. However, no classification scheme fits perfectly into pathophysiology, and the evolution of gastric atrophy involves different clinical and pathophysiological consequences. Gastric gland atrophy may be present in several lesions, especially gastritis, which can progress to the multifocal gastritis associated with the bacterium $H$. pylori and atrophic gastritis of the body, not dependent on the presence of the bacterium [11].

In view of the above, it is necessary to identify the prevalence with $H$. pillory infection, independently of associated lesions, in order to discuss these aspects with the purpose of contributing to their reduction. The study aimed to: 1) determine the prevalence of $H$. pylori in samples of gastric mucosa biopsies (antrum, body, cardia and fundus), obtained through upper digestive endoscopy and original reports of surgical pathology in a pathology laboratory Aracaju, Sergipe, Brazil; 2) correlate the presence of $H$. pylori in gastric biopsy material with the variables such as age, region (urban versus rural) and sex; 3) identify the types of lesions found in gastric mucosa with $H$. pylori positive; and 4) evaluate the association of the lesions found with the biopsied gastric mucosal region.

\section{Methodology}

Between January 2013 and December 2015, a cross-sectional, retrospective study was performed at the Laboratory of Pathological Anatomy Dra. Monica Araujo (LAPMA), in Aracaju,
Sergipe, based on the analysis of gastric mucosa reports obtained through biopsies of gastric mucosa from body, antrum, cardia and fundus, with $H$. pylori infection, regardless of whether through endoscopy and/or specimens of surgical resection. Reports from specimens of surgical resection were excluded because they presented incomplete information. During the research period, 45,206 biopsies were performed for the study of $H$. pylori from endoscopic gastric mucosa biopsy. Of this total, 13,986 reports were evaluated because they presented a positive result for the bacterium, and 1,077 were excluded because they did not meet the inclusion criteria, i.e., all reports should present the patients' demographic data, histopathological characteristics of the biopsied regions of the gastric mucosa and positivity for $H$. pylori. The final sample consisted of 12,909 biopsy reports.

A questionnaire was used as a data collection tool to identify the anatomopathological profile of the mucosa, which consisted of a tab with multiple-choice and short-text questions, elaborated by the researchers, having as dependent variable, the existence of $H$. pylori and independent variables: the patients' demographic characteristics (name, age, urban vs. rural region and sex); the histopathological characteristics of the antrum, fundus, cardia and body regions of the gastric mucosa such as the presence of chronic inflammation and inflammatory activity; glandular atrophy; intestinal metaplasia; evidence of ulcerated lesion; presence of fibrinoleukocytic crust, foveolar hyperplasia, lymphoid follicles, granulomas and other alterations, and the intensity of $H$. pylori colonization. The degree of intestinal metaplasia, classification of glandular atrophy and intensity of $H$. pylori colonization were performed according to the Sydney System [11]. The histological diagnosis of gastritis with and without $H$. pylori infection based on the Sydney System allowed to classify it histologically and to identify its topographic distribution from gastric biopsy.

As for the methodology used for the staining of the gastric biopsy fragments, for the histological examination, the fragments were deposited in bottles identified topographically, containing $10 \%$ formalin solution and led to a routine histological process, then subjected to $5 \mu \mathrm{m}$ cuts and stained with hematoxylin-eosin and Giemsa.

To analyze the data, descriptive and inferential analyses were performed. In the descriptive ones, the categorical variables were presented by means of simple frequency and percentage, as for the continuous ones, through mean and standard deviation (SD). In the inferential analysis, Pearson's Chi-square association and line tests were used. In order to evaluate the histopathological profile of the biopsied regions of the gastric mucosa, the perceptual map was constructed from the multiple correspondence analyses. The significance level adopted was $5 \%$ and the software used for the analysis was IBM SPSS Statistics 20.0. The study was approved by the Committee of Ethics and Research of the Universidade Tiradentes-CEP/UNIT (CAAE: 49195515.4.0000.5371).

\section{Results}

Endoscopic gastric biopsies totaled a sample of 45,206 biop- 


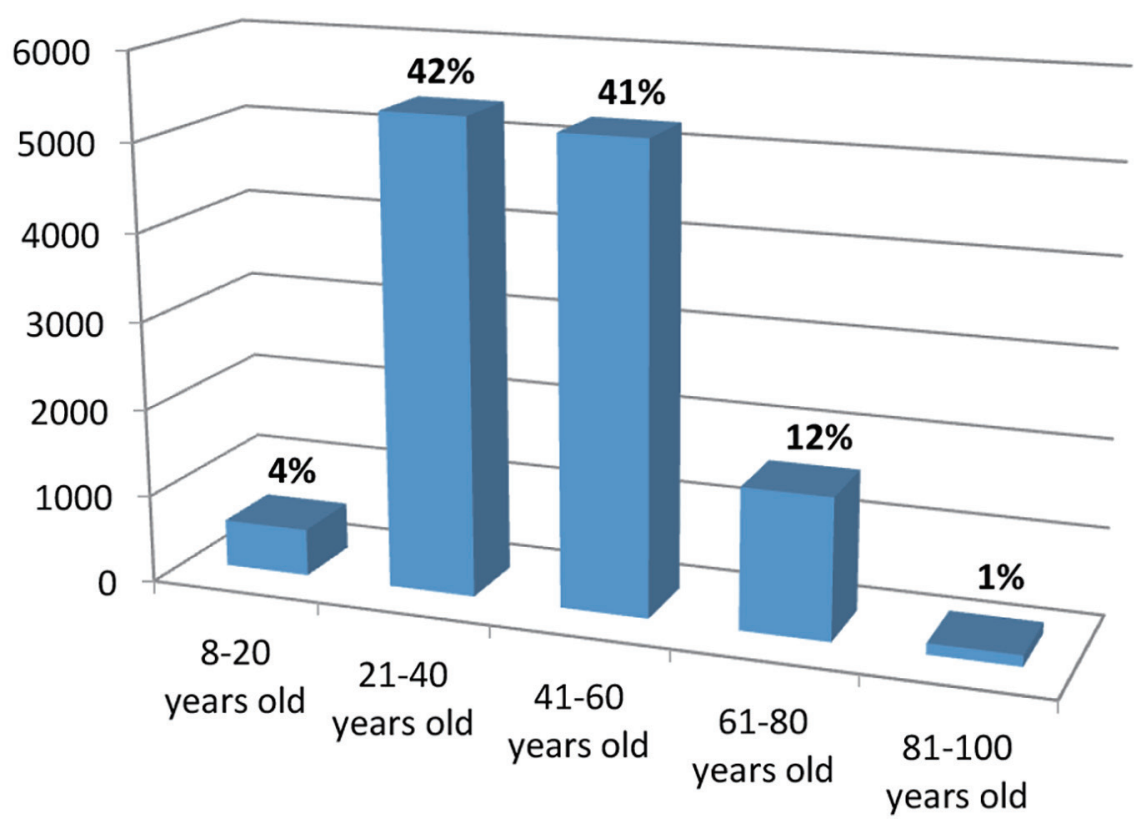

Figure 1. Age group of patients with positive H. pylori infection.

sies. Of the total sample, 13,986 were $H$. pylori positive, which translates into a prevalence of $30.93 \%(45,206)$. For data analysis, 12,909 reports met the inclusion criteria. Regarding sociodemographic variables, $8,320(64.5 \%)$ of the samples were female and 4,589 (35.5\%) were male. Of the samples, 8,647 $(72.3 \%)$ were from urban areas. The mean age (SD) was 43 years $(14.5 \%)$, and the age range of the sample varied from 8 to 100 years, being more prevalent between 21 and 60 years (Fig. 1).

As for the prevalence of gastric mucosa types and levels of infection, the antral mucosa was stated to appear the most representative fragment, corresponding to $95.5 \%(12,322)$ of the samples. It was also observed that $45.4 \%(5,857)$ of them had mild infection and $43.3 \%(5,587)$ presented moderate infection levels (Table 1).

The lesions were characterized as: glandular atrophy, intestinal metaplasia (specialized glands of the gastric body are replaced by intestinal type cells), ulcerations (gastric and duodenal ulcers), fibrinoleucocytic crust, foveolar hyperplasia, lymphoid follicles, granulomas, in addition to chronic inflammation and evidence of inflammatory activity. The absence of glandular atrophy was observed in $93.2 \%(12,033)$ of the biopsies. The mild type level of angular atrophy appeared in $6.1 \%(793)$ of the samples. In this study, $89.5 \%(11,548)$ of the cases had no intestinal metaplasia. In the $10.5 \%$ of cases with intestinal metaplasia, focal type was the most frequent when compared to diffuse and multifocal metaplasia. Some of the histologic features examined in this study were shown in Figures 2 and 3.

The presence of lymphoid follicles was more often observed compared to other alterations found (gastric and duodenal ulceration, fibrinoleucocytic crust, presence of foveolar hyperplasia and granulomas) (Table 2).
Regarding the relationship between the inflammatory process and the biopsied regions of the gastric mucosa, in all the regions evaluated, there was predominance of moderate degree, both in chronic inflammation and in the presence of inflammatory activity (Table 3 ).

Comparing the histopathological findings between the antrum and other regions of the stomach, the antral region has a higher rate $(\mathrm{P}<0.001)$ of glandular atrophy, H. pylori infection level, presence of foveolar hyperplasia and lymphoid follicles (Table 4).

In the fundic region, an evidence of fibrinoleucocytic crust and lymphoid follicles were significant $(\mathrm{P}<0.001)$ when compared to other regions of the gastric mucosa (Table 5).

Through the multiple correspondence analyses, the anato-

Table 1. Prevalence of Gastric Mucosa Types Represented in the Study and Levels of $H$. pylori Infection

\begin{tabular}{|lll|}
\hline \multicolumn{1}{|l}{} & $\mathbf{N}$ & $\mathbf{\%}$ \\
\hline Mucosa type & & \\
\hline Antrum & 12,322 & 95.5 \\
\hline Fundus & 6,058 & 46.9 \\
\hline Antrum and fundus & 5,504 & 42.6 \\
Cardia & 3 & 0.02 \\
\hline Body & 62 & 0.5 \\
\hline Antral-fundic transition & 75 & 0.6 \\
\hline H. pylori infection levels & & \\
Mild & 5,857 & 45.4 \\
$\quad$ Moderate & 5,587 & 43.3 \\
Severe & 1,465 & 11.3 \\
\hline
\end{tabular}



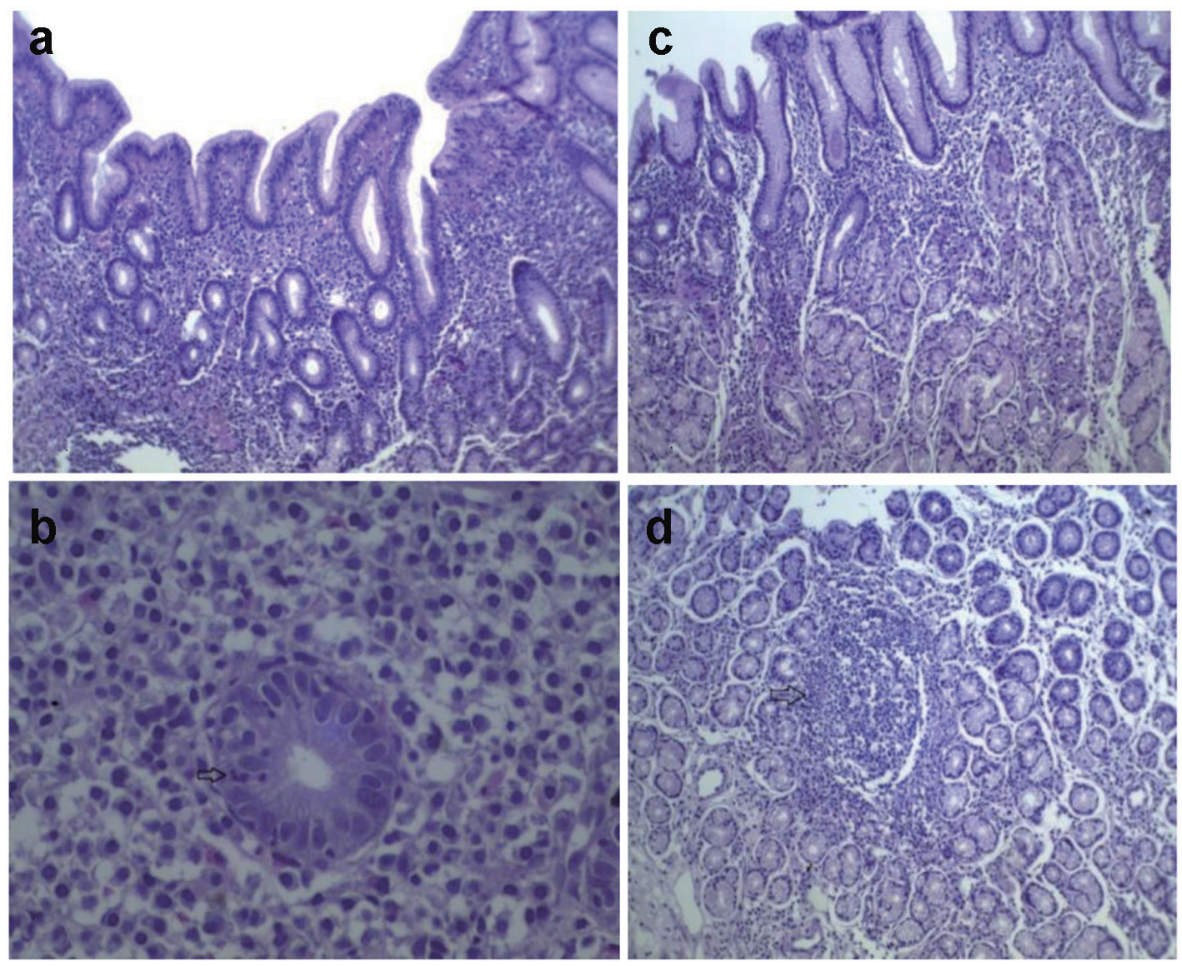

Figure 2. Histological section of gastric mucosa with H. pylori chronic gastritis. (A) Gastritis. (B) Inflammatory activity. (C) Oxyntic mucosal gastritis. (D) Lymphoid follicle (arrow) (H\&E, × 100).

mopathological profile of the antral and fundic mucosa was observed due to the proximity between the objects. In the antral mucosa, in addition to the presence of $H$. pylori degrees of mild to moderate, there was significant relationship with the absence of glandular atrophy, absence of associated ulcerated lesions and absence of intestinal metaplasia (Fig. 4).

Fundic mucosa displayed a strong association with the lymphoid follicles, partially linked to the mild and moderate levels of $H$. pylori infection, partially associated with the absence of glandular atrophy and absence of foveolar hyperplasia (Fig. 5).

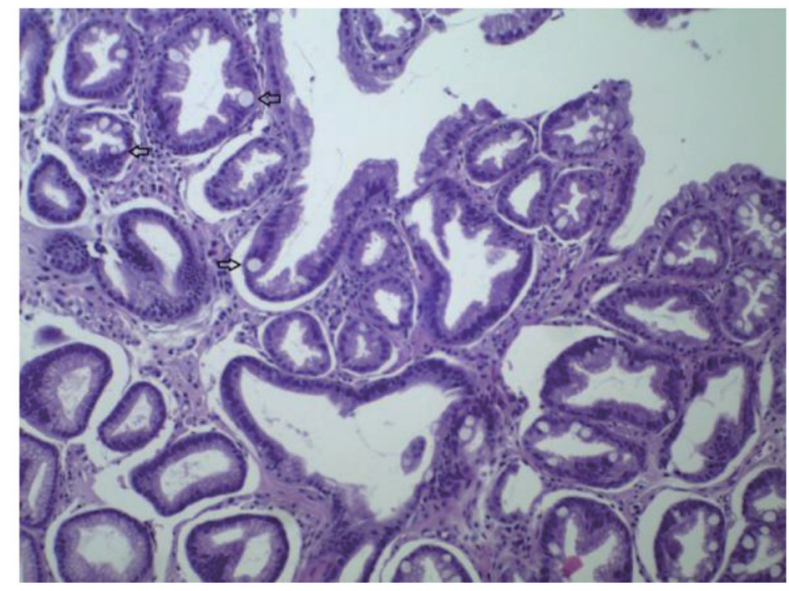

Figure 3. Antral mucosa with intestinal metaplasia (H\&E, × 100).

\section{Discussion}

Evidence estimates that $50 \%$ of the world population is affected by $H$. pylori. It is considered the commonest bacterial

Table 2. Histopathologic Findings of the Gastric Mucosa in Patients With Positive H. pylori Infection

\begin{tabular}{|lll}
\hline & N & \% \\
\hline Glandular atrophy & & \\
$\quad$ Absent & 12,033 & 93.23 \\
Mild & 793 & 6.14 \\
$\quad$ Moderate & 75 & 0.58 \\
$\quad$ Severe & 5 & 0.04 \\
Metaplasia classification & & \\
$\quad$ Absent & 11,548 & 89.5 \\
$\quad$ Focal & 939 & 7.3 \\
$\quad$ Multifocal & 310 & 2.4 \\
$\quad$ Diffuse & 112 & 0.9 \\
Evidence of ulcerated injury & 538 & 4.2 \\
Fibrinoleukocytic crust & 289 & 2.2 \\
Foveolar hyperplasia & 2,033 & 15.7 \\
Lymphoid follicles & 8,001 & 62 \\
Granulomas & 23 & 0.2 \\
\hline
\end{tabular}


Table 3. Correlation Between Inflammation and Biopsied Gastric Regions in Patients With Positive H. pylori Infection

\begin{tabular}{|c|c|c|c|c|c|c|c|c|c|c|}
\hline & \multicolumn{2}{|c|}{ Antral } & \multicolumn{2}{|c|}{ Fundus } & \multicolumn{2}{|c|}{ Cardia } & \multicolumn{2}{|c|}{ Body } & \multicolumn{2}{|c|}{$\begin{array}{c}\text { Antral-fundic } \\
\text { transition }\end{array}$} \\
\hline & $\mathbf{N}$ & $\%$ & $\mathbf{N}$ & $\%$ & $\mathbf{N}$ & $\%$ & $\mathbf{N}$ & $\%$ & $\mathbf{N}$ & $\%$ \\
\hline \multicolumn{11}{|c|}{ Chronic inflammation } \\
\hline Absent & 5 & 0.04 & 91 & 1.5 & 0 & 0 & 1 & 1.6 & 0 & 0 \\
\hline Mild & 1,599 & 12.97 & 1,324 & 21.9 & 0 & 0 & 20 & 31.7 & 2 & 2.7 \\
\hline Moderate & 8,335 & 67.64 & 3,875 & 64 & 2 & 66.7 & 41 & 65.1 & 56 & 74.7 \\
\hline Severe & 2,383 & 19.33 & 768 & 12.7 & 1 & 33.3 & 1 & 1.6 & 17 & 22.7 \\
\hline \multicolumn{11}{|c|}{ Inflammatory activity } \\
\hline Absent & 506 & 4.1 & 514 & 8.5 & 0 & 0 & 6 & 9.7 & 7 & 9.3 \\
\hline Mild & 4,934 & 40 & 2,495 & 41.2 & 1 & 33.3 & 25 & 40.3 & 31 & 41.3 \\
\hline Moderate & 6,024 & 48.9 & 2,809 & 46.3 & 1 & 33.3 & 30 & 48.4 & 32 & 42.7 \\
\hline Severe & 858 & 7.0 & 240 & 4 & 1 & 33.3 & 1 & 1.6 & 5 & 6.7 \\
\hline
\end{tabular}

infection in humans $[12,13]$. The prevalence of infection varies from age to age, ethnicity and especially socioeconomic status which is an important determinant and inversely correlated with the infection $[4,6]$.

The present study displayed a $H$. pylori infection preva- lence of $30.93 \%$. Previous studies [14-16] ranged from $26.91 \%$ to $76 \%$ in prevalence putting the present study close to the lower range point. Although the literature points out that $H$. pylori serum-prevalence is equally distributed in men and women, in this study, females had a higher prevalence, and the mean age

Table 4. Correlation Between Histopathological Findings of Antral Region and Other Locations of the Gastric Mucosa in H. pylori Positive Patients

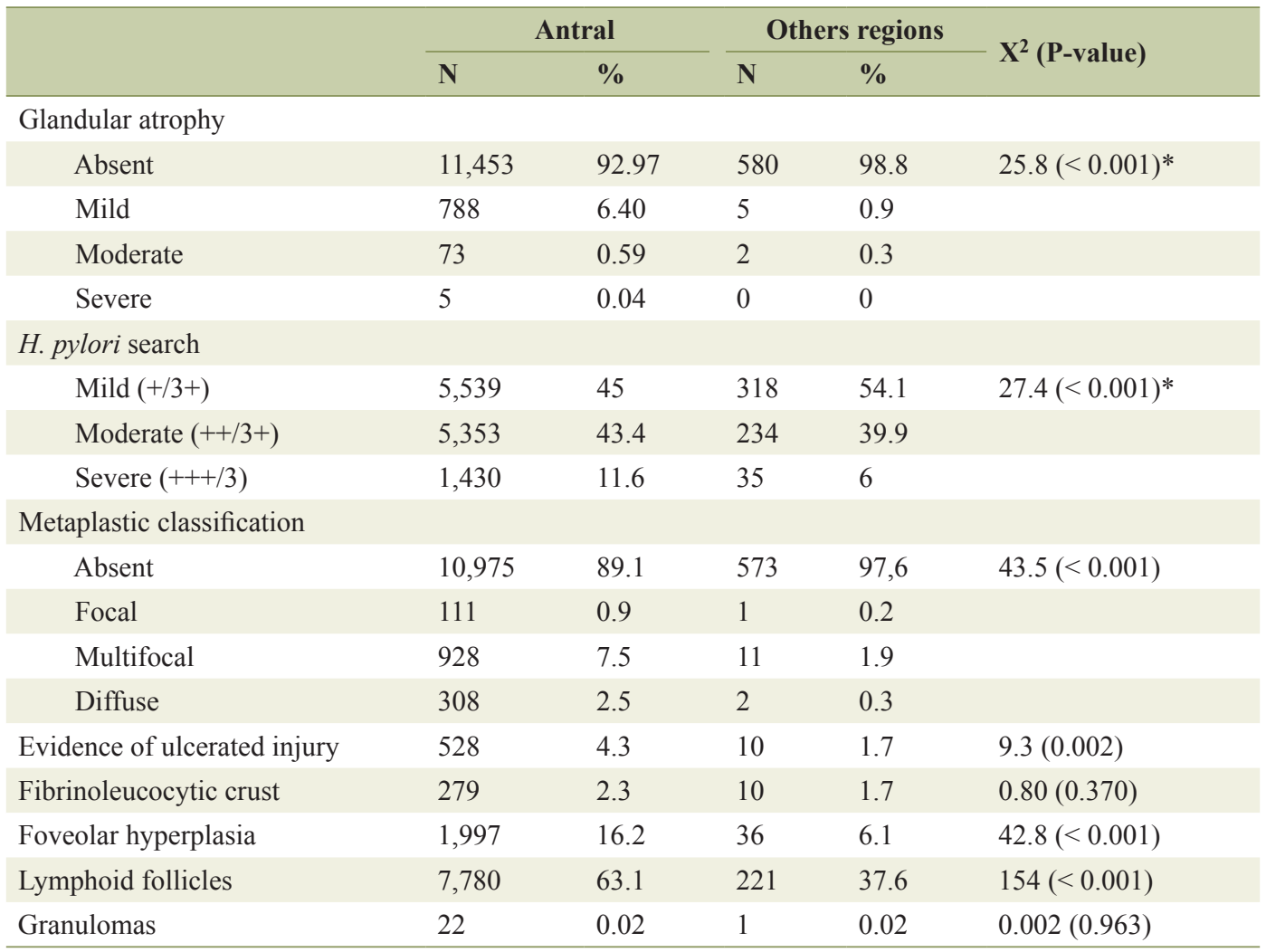

$\mathrm{X}^{2}$ : Chi-square test. *Linear association. 
Table 5. Correlation Between Histopathological Findings of Fundus and Other Locations of the Gastric Mucosa in $H$. pylori Positive Patients

\begin{tabular}{|c|c|c|c|c|c|}
\hline & \multicolumn{2}{|c|}{ Fundus } & \multicolumn{2}{|c|}{ Other regions } & \multirow{2}{*}{$X^{2}$ (P-value) } \\
\hline & $\mathbf{N}$ & $\%$ & $\mathbf{N}$ & $\%$ & \\
\hline \multicolumn{6}{|l|}{ Glandular atrophy } \\
\hline Absent & 5,688 & 93.92 & 6,345 & 92.63 & $9.6(0.002)^{*}$ \\
\hline Mild & 339 & 5.60 & 454 & 6.63 & \\
\hline Moderate & 27 & 0.45 & 48 & 0.7 & \\
\hline Severe & 2 & 0.03 & 3 & 0.04 & \\
\hline \multicolumn{6}{|l|}{ H. pylori infection levels } \\
\hline Mild $(+/ 3+)$ & 2,807 & 46.3 & 3,050 & 44.5 & $5.6(0.018)^{*}$ \\
\hline Moderate $(++/ 3+)$ & 2,595 & 42.8 & 2,992 & 43.7 & \\
\hline Severe $(+++/ 3+)$ & 656 & 10.8 & 809 & 11.8 & \\
\hline \multicolumn{6}{|l|}{ Metaplastic classification } \\
\hline Absent & 5,451 & 90 & 6,097 & 89 & $5.7(0.127)$ \\
\hline Focal & 55 & 0.9 & 57 & 0.8 & \\
\hline Multifocal & 424 & 7 & 515 & 7.5 & \\
\hline Diffuse & 128 & 2.1 & 182 & 2.7 & \\
\hline Evidence of ulcerated injury & 257 & 4.2 & 281 & 4.1 & $0.16(0.690)$ \\
\hline Fibrinoleucocytic crust & 97 & 1.6 & 192 & 2.8 & $21.2(<0.001)$ \\
\hline Foveolar hyperplasia & 1,015 & 16.8 & 1,018 & 14.5 & $8.7(0.003)$ \\
\hline Lymphoid follicles & 3,984 & 65.8 & 4,017 & 58.6 & $69.3(<0.001)$ \\
\hline Granulomas & 15 & 0.2 & 8 & 0.1 & $3.09(0.079)$ \\
\hline
\end{tabular}

$\mathrm{X}^{2}$ : Chi-square test. *Linear association.

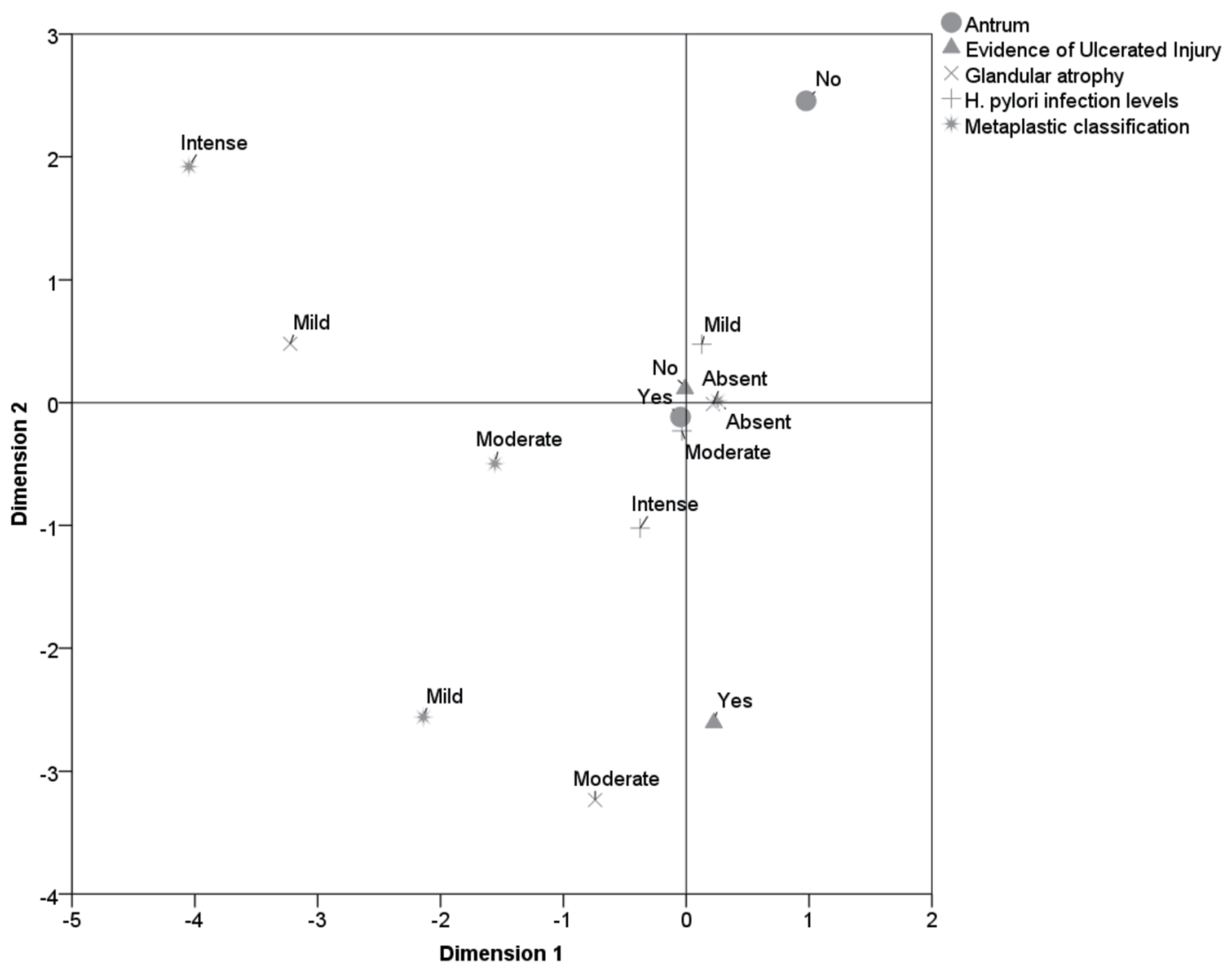

Figure 4. Pathological profile of the antral mucosa. 


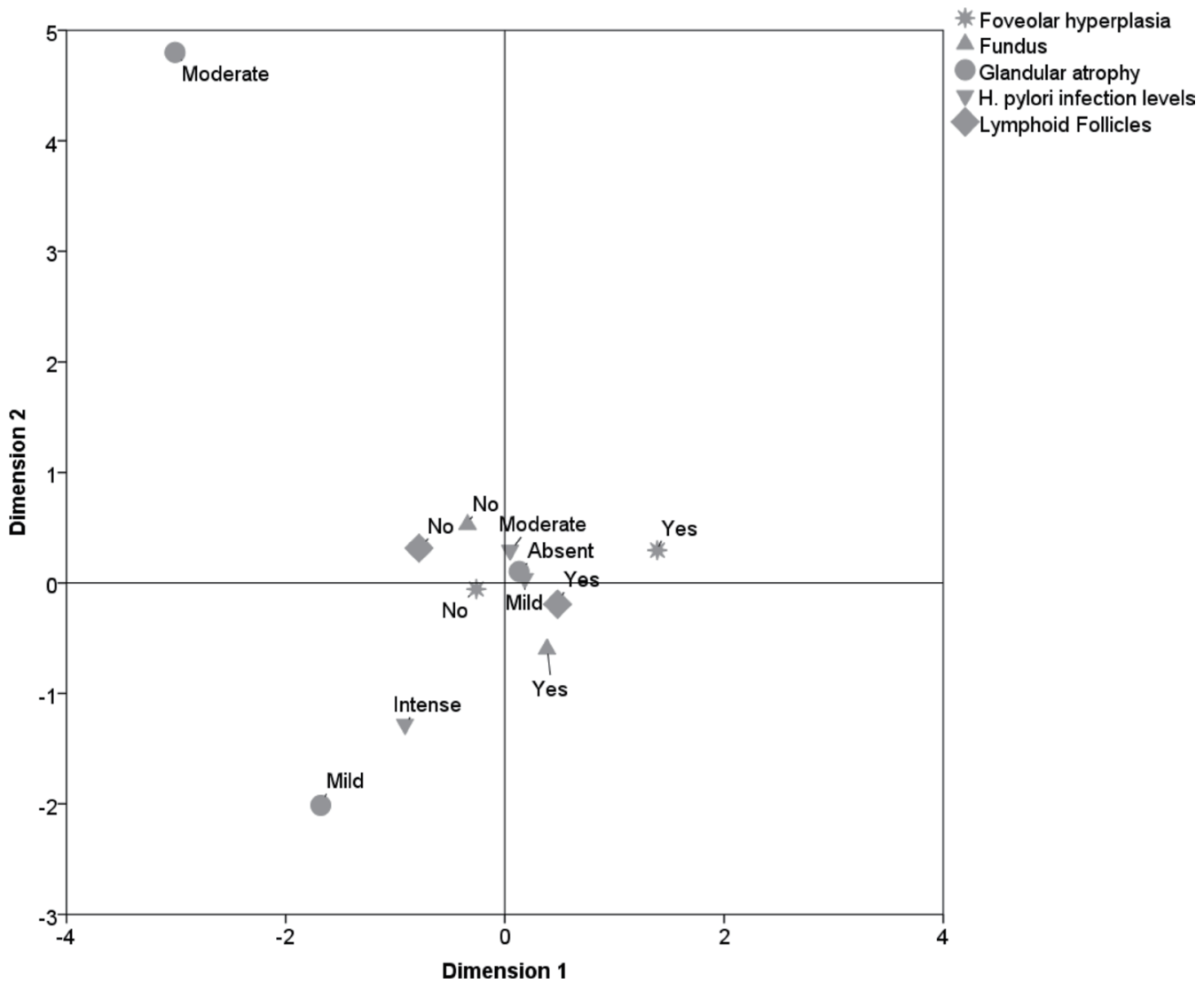

Figure 5. Pathological profile of the fundic mucosa.

of the infected was 43 years [13, 17]. The predominant age group ranged from 21 to 60 years $(83 \%)$, whereas in developed countries, such as the United States, serologic values ?? of $H$. pylori are rarely found before the age of 10 . Between the age of 18 and 30 , these values reach $10 \%$ and increase to $50 \%$ in people over 60 [4]. In developing nations, where most children are infected before the age of 10 , the prevalence in adults reaches more than $80 \%$ before the age of 50 [4]. In Brazil, Bedoya et al [18] made a comparison with several diagnostic tests and reported a prevalence of $34 \%$ in children and young people up to 18 years old, increasing significantly over aging process.

Evaluating the level of intensity regarding the presence of H. pylori in the biopsied material, it was found that the mild and moderate levels predominated in all gastric regions. No studies supporting these findings could be found in literature.

The pathological profile of the gastric mucosa displayed presence of chronic inflammation and inflammatory activity in a moderated level in almost all biopsied regions, except for the region of the cardia, in relation to the inflammatory activity. According to Hagymasi et al [19], H. pylori-induced continuous inflammation, usually confined to the antrum, alters the physiology of gastric acid secretion to varying degrees, leading to chronic gastritis, which in most individuals does not further evolve.

Evidence points out that chronic gastritis induced by $H$. pylori affects the stomach's antrum and body mucosa in most of the cases [20,21]. A study conducted in Brazil by Alvares et al [22] identified a prevalence of $88.4 \%$ of chronic gastritis in H. pylori positive patients, with significantly more inflammation in the antrum and angular incisure than in the gastric body. In the present study, evidence of ulcerated lesions was found in $4.2 \%$ of the $H$. pylori positive samples evaluated. Antral and fundic regions presented similar results, with a prevalence of $4.3 \%$ and $4.2 \%$, respectively.

Odze and Goldblum [23] stated that although H. pylori infects more than half of the world's population, only $1-3 \%$ of the patients infected develop gastric adenocarcinoma. Therefore, a prevalence of glandular atrophy and intestinal metaplasia in the samples was evaluated. Glandular atrophy was absent in $93.2 \%$ of the $H$. pylori positive samples. Gastric intestinal metaplasia defined as the replacement of the surface, foveolar and glandular epithelium in the oxyntic or antral mucosa by the intestinal epithelium was absent in $89.5 \%$ of the samples.

Lymphoid follicles appear within a week after the onset of acute $H$. pylori infection, and are unusual on healthy/uninfected gastric mucosa [24]. Histopathological changes like foveolar hyperplasia and lymphoid follicles have shown, in the analyzed samples, a significant association with $H$. pylori. However, the evidence of ulcerated lesions in the antral region and fundic region did not support the idea that the presence of $H$. pylori represents significant development of either type of ulcerated lesion. The data showed that the lymphoid follicles were evidenced in $62 \%$ of the $H$. pylori positive gastric 
biopsy samples, evidenced the hypothesis of an important link between lymphoid follicles and infection [25]. The presence of foveolar hyperplasia in the gastric mucosa occurs in patients with normal histological presentation of gastric mucosa. It may, however, be a consequence of chronic inflammation and its association with $H$. pylori [26]. This finding had significant value $(\mathrm{P}<0.001)$ in both the antrum and fundic regions.

It is known that $H$. pylori infection is characterized by a transient increase in acid secretion and hypochlorhydria, being a precursor for the development of active chronic gastritis, with a dense cellular infiltrate in the mucosa, which due to its persistence can cause serious damage to the gastric mucosa, which can progress to atrophic gastritis, glandular atrophy and intestinal metaplasia. The infection by the micro-organism is characterized by chronicity, which predisposes its participation in the pathogenesis of chronic gastritis, peptic ulcers (gastric and duodenal), adenocarcinoma, gastric lymphoma and recurrent abdominal pain.

\section{Acknowledgments}

The patologist Dra. Monica Lima de Araujo and the Laboratory of Pathological Anatomy Dra. Monica Araujo (LAPMA).

\section{Financial Support}

None.

\section{Conflicts of Interest}

None.

\section{References}

1. Marshall BJ, Warren JR. Unidentified curved bacilli in the stomach of patients with gastritis and peptic ulceration. Lancet. 1984;1(8390):1311-1315.

2. Amieva MR, El-Omar EM. Host-bacterial interactions in Helicobacter pylori infection. Gastroenterology. 2008;134(1):306-323.

3. Kao CY, Sheu BS, Wu JJ. Helicobacter pylori infection: An overview of bacterial virulence factors and pathogenesis. Biomed J. 2016;39(1):14-23.

4. Bittencourt PFS, Rocha GA, Penna FJ, Queiroz DMM. Ulcera peptica gastroduodenal e infeccao pelo Helicobacter pylori na crianca e adolescente. Jornal De Pediatria. 2006;82(5):325-334.

5. Marshall BJ. History of the discovery of C. pylori. In: Blaser MJ (Ed). Campylobacter Pylori in Gastritis and Peptic Ulcer Disease. New York: Igaku-Shoin. 1989; p. 7-23.

6. Eusebi LH, Zagari RM, Bazzoli F. Epidemiology of Helicobacter pylori infection. Helicobacter. 2014;19(Suppl $1): 1-5$.
7. Nagy P, Johansson S, Molloy-Bland M. Systematic review of time trends in the prevalence of Helicobacter pylori infection in China and the USA. Gut Pathog. 2016;8:8.

8. Machida-Montani A, Sasazuki S, Inoue M, Natsukawa S, Shaura K, Koizumi Y, Kasuga Y, et al. Association of Helicobacter pylori infection and environmental factors in non-cardia gastric cancer in Japan. Gastric Cancer. 2004;7(1):46-53.

9. Calvet X, Ramirez Lazaro MJ, Lehours P, Megraud F. Diagnosis and epidemiology of Helicobacter pylori infection. Helicobacter. 2013;18(Suppl 1):5-11.

10. Robinson K, Argent RH, Atherton JC. The inflammatory and immune response to Helicobacter pylori infection. Best Pract Res Clin Gastroenterol. 2007;21(2):237-259.

11. Stolte M, Meining A. The updated Sydney system: classification and grading of gastritis as the basis of diagnosis and treatment. Can J Gastroenterol. 2001;15(9):591-598.

12. Go MF. Review article: natural history and epidemiology of Helicobacter pylori infection. Aliment Pharmacol Ther. 2002;16(Suppl 1):3-15.

13. Brown LM. Helicobacter pylori: epidemiology and routes of transmission. Epidemiol Rev. 2000;22(2):283-297.

14. Xu C, Yan M, Sun Y, Joo J, Wan X, Yu C, Wang Q, et al. Prevalence of Helicobacter pylori infection and its relation with body mass index in a Chinese population. Helicobacter. 2014;19(6):437-442.

15. Fashner J, Gitu AC. Diagnosis and Treatment of Peptic Ulcer Disease and H. pylori Infection. Am Fam Physician. 2015;91(4):236-242.

16. Wen S, Moss SF. Helicobacter pylori virulence factors in gastric carcinogenesis. Cancer Lett. 2009;282(1):1-8.

17. Goh KL, Chan WK, Shiota S, Yamaoka Y. Epidemiology of Helicobacter pylori infection and public health implications. Helicobacter. 2011;16(Suppl 1):1-9.

18. Bedoya A, Garay J, Sanzon F, Bravo LE, Bravo JC, Correa H, Craver R, et al. Histopathology of gastritis in Helicobacter pylori-infected children from populations at high and low gastric cancer risk. Hum Pathol. 2003;34(3):206213.

19. Hagymasi K, Herszenyi L, Tulassay Z. From Chronic Gastritis to Gastric Cancer: The Role of Helicobacter pylori. Helicobacter Pylori: A Worldwide Perspective 2014, Oak Park, IL. 2014:316-335.

20. Kusters JG, van Vliet AH, Kuipers EJ. Pathogenesis of Helicobacter pylori infection. Clin Microbiol Rev. 2006;19(3):449-490.

21. Zhang RG, Duan GC, Fan QT, Chen SY. Role of Helicobacter pylori infection in pathogenesis of gastric carcinoma. World J Gastrointest Pathophysiol. 2016;7(1):97107.

22. Alvares MMD, Marino M, Oliveira CA, Mendes CC, Costa ACF, Guerra J, Queiroz DMM, et al . Caracteristicas da gastrite cronica associada a Helicobacter pylori: aspectos topograficos, doencas associadas e correlacao com o status cagA. Jornal Brasileiro de Patologia e Medicina Laboratorial. 2006;42(1):51-59.

23. Odze RD, Goldblum JR. Inflammatory disorders of the stomach. Surgical Pathology of the Gastrointestinal 
Tract, Liver, Biliary Tract, and Pancreas. Philadelphia. 2009:285.

24. Hellstrom PM. Spotlight on gastroenterology - the Nobel Prize Laureates in Physiology or Medicine 2005: John Robin Warren and Barry James Marshall. Scand J Gastroenterol. 2005;40(12):1383-1385.
25. Lee I. Critical pathogenic steps to high risk Helicobacter pylori gastritis and gastric carcinogenesis. World J Gastroenterol. 2014;20(21):6412-6419.

26. Voutilainen M, Juhola M, Farkkila M, Sipponen P. Foveolar hyperplasia at the gastric cardia: prevalence and associations. J Clin Pathol. 2002;55(5):352-354. 